Original article

\title{
Predicting suicidal ideation by interpersonal variables, hopelessness and depression in real-time. An ecological momentary assessment study in psychiatric inpatients with depression
}

\author{
N. Hallensleben ${ }^{\mathrm{a}}$, H. Glaesmer ${ }^{\mathrm{a}}$, T. Forkmann ${ }^{\mathrm{b}, \mathrm{c}}$, D. Rath ${ }^{\mathrm{b}}$, M. Strauss ${ }^{\mathrm{d}}$, A. Kersting ${ }^{\mathrm{e}}$, \\ L. Spangenberga,* \\ a Department of Medical Psychology and Medical Sociology, University of Leipzig, Germany \\ ${ }^{\mathrm{b}}$ Institute of Medical Psychology and Medical Sociology, University Hospital of RWTH Aachen University, Germany \\ ${ }^{\mathrm{c}}$ Department of Clinical Psychology, University of Duisburg-Essen, Germany \\ d Department of Psychiatry, University of Leipzig, Germany \\ ${ }^{\mathrm{e}}$ Department of Psychosomatic Medicine and Psychotherapy, University of Leipzig, Germany
}

\section{A R T I C L E I N F O}

\section{Article history:}

Received 4 October 2018

Received in revised form 8 November 2018

Accepted 9 November 2018

Available online 5 December 2018

\section{Keywords:}

Suicidal ideation

Risk factors

Ecological momentary assessments

Interpersonal variables

Hopelessness

\begin{abstract}
A B S T R A C T
Objective: To extend evidence on the short-term variability of passive and active suicidal ideation (SI) and the association with suggested proximal risk factors such as interpersonal variables (perceived burdensomeness [PB], thwarted belongingness [TB], hopelessness, and depression) in real-time. Methods: This is an observational study using a prospective design applying ecological momentary assessments (EMA). Eligible for study inclusion were inpatients with unipolar depression, current or lifetime suicidal ideation, and fluent German. Over six days, 74 participants rated their momentary level of passive and active SI, PB, TB, depressiveness, and hopelessness up to 10 times per day on smartphones. Data was collected from August 2015 to July 2017. Compliance was excellent (89.7\%).

Results: Mean squared successive differences supported temporal instability for all variables. According intra-class correlations, between $25 \%$ and $47 \%$ of variance was accounted for by within-person variability. Multilevel analysis demonstrated significant positive associations between hopelessness, depressiveness, PB, and TB with passive SI. Prospectively, hopelessness and PB remained predictors of passive SI. For active SI, hopelessness, depression, PB, and TB were significantly associated cross-sectionally. Prospectively, hopelessness, PB, and the interaction PBxTB predicted active SI. All models were controlled for previous level of SI.

Conclusions: This study provides further evidence on the short-term variability of SI in very short time frames implying the need of assessing SI repeatedly in clinical and research settings. The associations between interpersonal variables and passive and active SI were only partial in line with assumptions of the Interpersonal Theory of Suicide. Overall, the effects were small warranting further investigation.
\end{abstract}

(c) 2018 Elsevier Masson SAS. All rights reserved.

\section{Introduction}

The major public health problem and personal tragedy of suicide is accompanied by a lack of empirical evidence regarding the short-term prediction of suicidal ideation (SI) and suicidal behavior (SB) [1], i.e. the processes leading to SI and SB in time frames of hours or days (proximal risk factors) [2,3]. Variables such as depressiveness, hopelessness, rage, anger, anxiety, and sleeping

\footnotetext{
* Corresponding author at: University of Leipzig, Department of Medical Psychology and Medical Sociology, Philipp-Rosenthal-Str. 55, 04103, Leipzig Germany.

E-mail address: Lena.Spangenberg@medizin.uni-leipzig.de (L. Spangenberg).
}

problems were identified as variables elevating suicide risk and increasing SI in the short-term while findings seem to be most robust for depressiveness and hopelessness [4-9].

Yet, a recent meta-analysis has concluded that the prediction of imminent suicide risk has not substantially improved over the past 50 years and pointed out the need of assessing suicidal phenomena repeatedly [3], e.g. because SI has been shown to fluctuate considerably $[10,11]$. Although it has not been established yet in detail, which factors determine the individuals' transition from suicidal thoughts to suicidal actions, the presence of SI is a major risk factor for the emergence of actual SB. Consequently, understanding the development of SI, the role of proximal risk factors and monitoring its course over time is an important part of suicide prevention. Studies applying ecological momentary 
assessments (EMA) allow examining variables of interest in real time, and in participants' natural environment [12,13] and are a very promising approach in suicide research $[1,14]$.

\subsection{The interpersonal theory of suicide}

The Interpersonal Theory of Suicide (IPTS) posits two interpersonal factors that lead to suicidal desire: thwarted belongingness (TB) and perceived burdensomeness (PB) [15]. TB describes the unmet need of being socially integrated, and $\mathrm{PB}$ reflects the perception of being a burden on others. The sole presence of one of these factors causes passive SI (i.e., having death wishes such as "I wish I was dead."), whereas the simultaneous presence of PB and TB (i.e., a two-way interaction) in connection with hopelessness regarding their decrease is assumed to lead to active SI (i.e., experiencing a desire to engage in suicidal behaviors such as "I want to kill myself.") [16]. TB and PB are assumed to be dynamic and, thus, modifiable cognitive-affective states $[15,16]$. According available empirical evidence, the strongest support has been found for the effect of PB and for the interaction of PB and TB on SI, while the association between TB and SI showed to be less consistent $[17,18]$. However, only very few studies have tested the main as well as the interaction effects of PB and TB proposed by the IPTS, have applied prospective designs, or have specifically focused on individuals at elevated risk for suicide $[17,18]$.

\subsection{EMA studies on SI}

Very few studies have examined SI and its risk factors employing EMA so far $[19,20]$ revealing a predictive effect for negative affective states on SI [6,21,22]. Regarding the short-term variability of SI, Kleiman et al. (2017) have reported substantial variability in SI within a time frame of four to eight hours demonstrating that a considerable amount of variation (33\%-47\%) in SI is attributable to within-person variance [10]. A preliminary analysis $(\mathrm{N}=20)$ of the present study has also demonstrated considerable fluctuations in SI within an even shorter time frame of $30 \mathrm{~min}$ up to two hours [11]. Variables discussed at proximal risk factors (hopelessness, $\mathrm{PB}$, and $\mathrm{TB}$ ) were as well subject to considerable within-person fluctuation and co-occurred with SI in cross-sectional multi-level analyses. However, in prospective multi-level analyses, neither hopelessness nor PB, or TB predicted short-term changes in SI when controlling for SI at the previous measurement occasion [10]. A recent daily diary study also demonstrated concurrent associations between SI and interpersonal variables and hopelessness and provided initial support for prospective associations between the interaction of interpersonal variables and SI [23].

\subsection{Aims}

Our study aims to further investigate the short-term variability of SI. In addition, we examined cross-sectional as well as prospective associations between SI and variables suggested as proximal risk factors by the IPTS (i.e. PB and TB, [15]) accounting for well-established risk factors of SI such as depressiveness (i.e. sad mood) and hopelessness [4,6,9]. We conducted an EMA study in a sample of psychiatric inpatients with unipolar depression, where we expected SI to occur frequently [24].

In order to extend current evidence and examine the assumptions of the ITPS more stringently [16,20], we 1) applied a high-frequency sampling scheme (10 signals per day within a time frame of 12 hours), 2) assessed all variables of interest with two items (ensuring reliable assessment) [25], 3) distinguished between passive and active SI, and 4) included the interaction between PB and TB in our analyses.

\section{Method}

\subsection{Procedure}

Eligible patients in three German psychiatric hospitals were approached and informed about the study by a research assistant $(\mathrm{N}=196)$. Informed consent was provided by those who were willing to participate $(\mathrm{N}=92)$. Of those, $17(18 \%)$ were excluded because they did not meet the inclusion criteria (i.e. primary diagnosis of unipolar depression, current or life-time SI, age $\geq 18$ years, fluent in German). Patients were further excluded if they had a bipolar affective disorder, psychotic symptoms, substance addiction in the past year, or an IQ below 85 according to a language based intelligence test [26]. Four participants from the pilot phase were additionally included in the study resulting in $\mathrm{N}=79$ patients.

Every participant received $10 €$ for compensation and additional $40 €$ if having completed at least $80 \%$ of the EMA prompts. All study procedures were approved by the Ethical Review Board of the Medical Faculty of University of Leipzig (No: 388-13-16122013).

\subsection{Participants}

Five of the included participants (6\%) did not finish the EMA assessment due to high strain $(\mathrm{n}=3)$ or unexpectedly early discharge from hospital $(n=2)$. Thus, data of 74 participants (collected $8 / 2015$ to $7 / 2017$ ) were analyzed ( $N=69$ with major depression, $\mathrm{N}=5$ with dysthymia). Age was between 18 and 85 years $(M=37.6, S D=14.3), N=53(71.6 \%)$ of the participants were female and $\mathrm{N}=24(33.8 \%)$ reported one or more prior suicide attempts.

\subsection{Assessments}

\subsubsection{Baseline}

Participants underwent a structured clinical interview (SCID-I) [27] to ensure diagnosis of depression.

\subsubsection{EMA}

EMA data collection was conducted via movisensXS [28] on Android smartphones that were lent to the participants. Participants were signaled 10 times per day on six consecutive days; signals occurred randomly between 8:00 a.m. and 7:50 p.m. with a minimum interval of 30 minutes between prompts (i.e. signal-contingent). At every prompt, participants were asked to rate their momentary level of passive (Life is not worth living for me.; There are more reasons to die than to live for me.) and active SI (I think about taking my life., I want to die.), depression (I feel sad., ... downhearted.), hopelessness (My future seems dark to me., I might as well give up because there is nothing I can do about making things better for myself.), PB (I feel useless., ... like a burden for others.), TB (I feel lonely., . . . like I do not belong.). Each construct was measured with two items using a 5-point Likert scale $(1-n o t$ at all to 5 - extremely) resulting in sum scores (ranging from 2 to 10) with higher values indicating a higher level of the respective construct.

EMA items were taken from existing EMA instruments (e.g., German PANAS-X [29]), selected from relevant self-report instruments considering item-total correlation, item content and wording (e.g., the Interpersonal Needs Questionnaire (INQ) [30,31], the German Beck Hopelessness Scale (BHS) [32], the Paykel Suicide Scale (PSI) [33], the Modified Scale for Suicidal Ideation (MSSI) [34], the German Beck Scale for Suicide Ideation (BSS) [35]), or were newly developed. In a second step, item wording was adjusted to be as brief as possible and to refer to the actual moment. Confirmatory factor analysis on the within-person 
covariance matrix supported the factorial validity of the item set with depression, hopelessness, PB, TB, passive and active SI reflecting different latent constructs. Reliabilities were excellent on the person-level $(\omega \geq .90)$ and good at the prompt-level $(\omega \geq .70)$ for all constructs considered in the analysis. Convergent validity was indicated by positive correlations (all $r \geq .55$ ) between mean EMA scores and sum scores of self-report questionnaires filled in after the EMA assessment measuring the same construct (i.e., INQ BHS, BSS and the Rasch-based Depression Screening (DESC) [36]) [25].

\subsection{Data analysis}

The dataset consisted of 60 (assessments on level 1) * 74 (persons on level 2) $=4,440$ observations. Participants completed $89.7 \%$ of the EMA assessments on average ( $\mathrm{Min}=75 \%$, $\mathrm{Max}=100 \%$ ), resulting in 4,295 valid observations. Due to the nested structure of the data, we conducted multilevel analyses using the statistical software HLM [37]. Figures were created by using R, ggplot2 package $[38,39]$.

In a first step, we calculated the intercept-only model for both outcomes (passive and active SI) and intra-class correlations (ICC) as an indicator of the proportion of variance explained by the different levels [40]. To further describe variability across time, we calculated Mean Squared Successive Differences (MSSD). The MSSD is a sum score of the squared differences between two measurement occasions in time series and thus represents pointto-point variability with higher values indicating higher fluctuation [41].

Secondly, we computed a baseline model for both outcome variables. The baseline models contained the time lagged SI (passive or active) at level 1 to account for autocorrelation of SI in all further models. These models were used as reference models to evaluate the incremental value of the level 1 predictors using a Quasi $R^{2}$ measure indicating the change of the outcome's residual variance when adding the model's level 1 predictors $[40,42]$. We used the $\mathrm{R}^{2}$ (S\&B) formula [43], as this can be applied to models containing random slopes [44].

Thirdly, two models were fitted for passive SI (model 1 with cross-sectional predictors at level 1 , model 2 with time-lagged predictors at level 1) and four for active SI (model 3a and 3b with cross-sectional predictors at level 1 , model $4 \mathrm{a}$ and $4 \mathrm{~b}$ with timelagged predictors at level 1 , the latter including the interaction term PBxTB). Besides the recommendation to generally allow random slopes in the model where applicable [45], we conducted deviance tests for all models revealing better fit for the random slopes models in comparison to the more restrictive random intercept model. Yet, because we were primarily interested in the fixed effects, random effects are not reported in the paper besides the estimated percentage of slope coefficients that are positive [40].
All models were estimated by means of restricted maximum likelihood estimation (REML), as our number of level 2 units is relatively small [42] and the predictor variables were person-mean centered in all analyses, as we were particularly interested in within-person relationships [46]. In models 2 and 4, predictors were time lagged to the previous measurement occasion $(t-1)$. In doing so, the last value per day was not lagged to avoid obtaining "between-days" lags. Our analyses were sufficiently powered to detect moderate to large effects on the observational level (level 1) [47].

\section{Results}

\subsection{Short-term variability}

Across all assessments, the proportion of SI nonzero ratings was $64.3 \%$ for passive SI and $38.9 \%$ for active SI. Two participants (3\%) did not report any SI and 13 participants (18\%) did not report any active SI. ICCs indicate that in hopelessness and passive SI around $25 \%$ of the variance is accounted for by within-person variability. For active SI, TB, PB, and depressiveness, between $36 \%$ and $47 \%$ of variance is due to within-person variability according ICCs (see Table 1). Mean MSSD values illustrate that there was on average considerable moment-to-moment variability in all constructs. Yet, MSSDs showed a wide range, indicating that this variability differed substantially between individuals (see Table 1). In Fig. 1, heat maps visually illustrate individual moment-to-moment variability for SI and the risk factors.

\subsection{Multilevel analyses}

\subsubsection{Outcome passive SI}

Depressiveness, hopelessness, PB, and TB are significantly positively associated with passive SI, beyond the effects of time lagged passive SI (model 1). For the majority of participants (71-97\%), the associations between predictors in model 1 and passive SI were positive (see ratio of slopes $>0$ in Table 2 ).

In model 2, the levels of hopelessness, PB, and passive SI at t-1 significantly positively predicted passive SI at time $t$. Contrary to our expectations, time lagged TB and depressiveness did not predict passive $S I$ at time $t$, which was accompanied by lower ratios of positive slopes (60\% for depressiveness and $50 \%$ for $\mathrm{TB}$ ).

\subsubsection{Outcome active SI}

When considering the main and interaction effects of the interpersonal variables cross-sectionally (model $3 a$ and $3 b$ ), depressiveness, hopelessness, TB, and $\mathrm{PB}$ were positively significantly associated with active SI (co-occurred). For TB and PB, between 64 and $70 \%$ of participants showed positive associations with active SI (see Table 3 ).

Table 1

Descriptive statistics and variability indices of the EMA scales.

\begin{tabular}{|c|c|c|c|c|c|c|c|c|c|}
\hline Construct and items & Mean & SD & Min & Max & Mean MSSD & SD MSSD & $\operatorname{Min}_{\text {MSSD }}$ & $\operatorname{Max}_{\text {MSSD }}$ & ICC \\
\hline Depressiveness & 5.88 & 1.81 & 2.28 & 9.54 & 3.58 & 2.39 & .53 & 12.08 & 0.53 \\
\hline Perceived burdensomeness & 5.41 & 2.08 & 2.12 & 9.78 & 2.60 & 1.89 & .15 & 8.47 & 0.66 \\
\hline Thwarted belongingness & 5.13 & 1.95 & 2.02 & 9.87 & 3.52 & 2.62 & .03 & 11.79 & 0.57 \\
\hline Hopelessness & 5.50 & 2.25 & 2.02 & 9.97 & 2.00 & 1.58 & .03 & 6.71 & 0.74 \\
\hline Passive suicidal ideation & 4.54 & 2.25 & 2.00 & 9.64 & 1.95 & 2.02 & .00 & 9.05 & 0.75 \\
\hline Active suicidal ideation & 3.18 & 1.50 & 2.00 & 8.06 & 1.39 & 2.10 & .00 & 12.83 & 0.64 \\
\hline
\end{tabular}

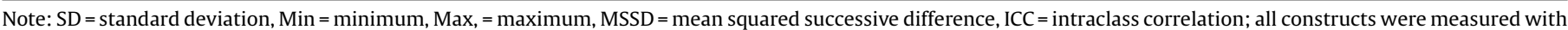
two items resulting in a sum score from 2 to 10 ;

Data in this table was presented in Forkmann et al. (in press) ${ }^{25}$, as part of a large psychometric analysis of the EMA item set used in this study. 


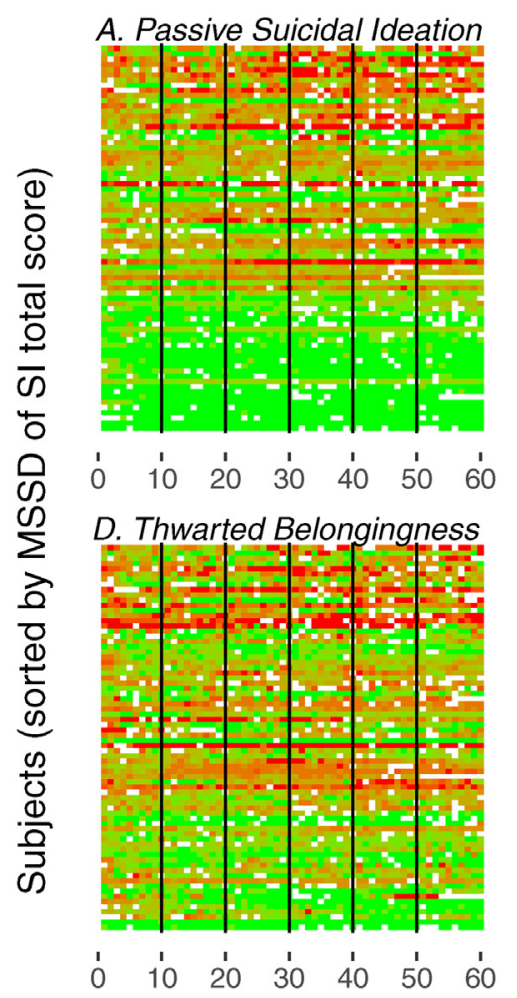

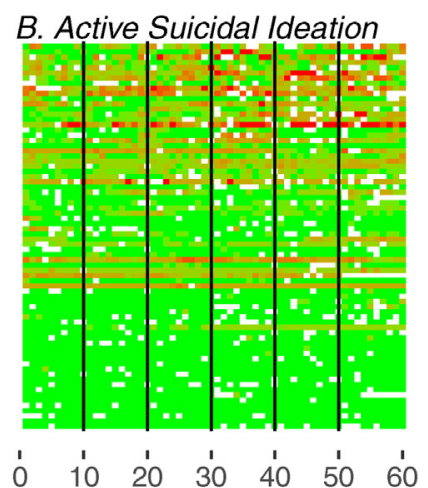

\section{E. Depressiveness}

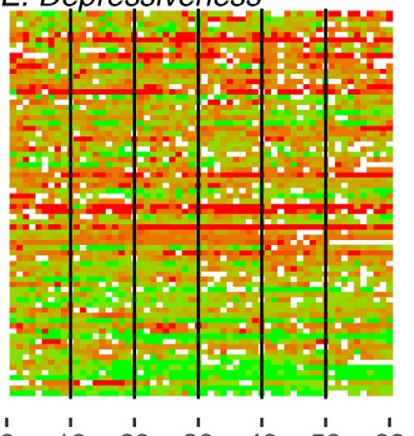

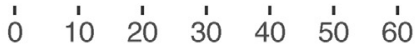

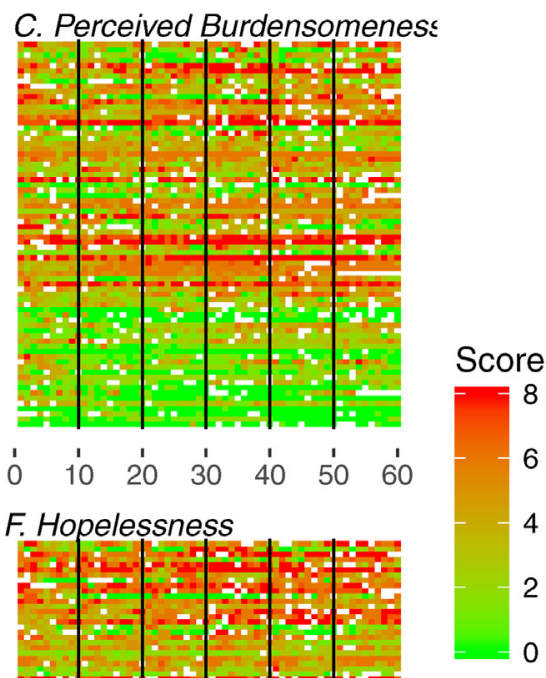

Observations

Fig. 1. Heat maps of momentary ratings of suicidal ideation and risk factors across observations and participants.

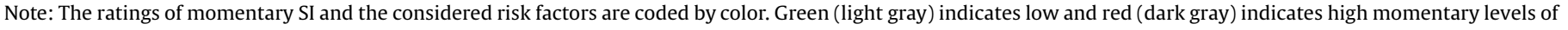
the respective construct. Missing observations are not colored.

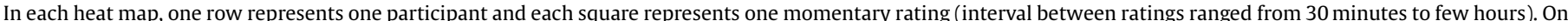

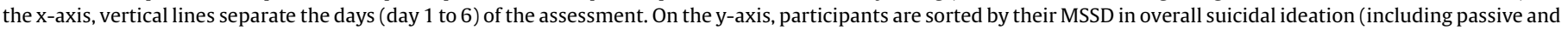

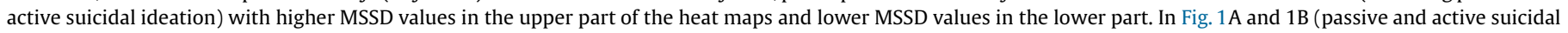

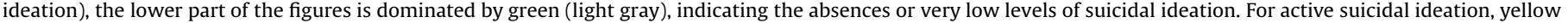

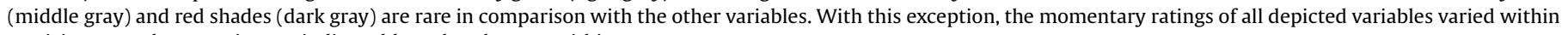
participants and across time as indicated by color changes within rows.

In the prospective models $4 \mathrm{a}$ and $4 \mathrm{~b}$, TB did not predict active SI, while hopelessness, $\mathrm{PB}$, and the interaction of $\mathrm{PB}$ and $\mathrm{TB}$ at $\mathrm{t}-1$ significantly predicted active SI (see Table 3).

\section{Discussion}

\subsection{Short-term variability of SI}

The results further demonstrated that SI as well as the risk factors under study (i.e., PB, TB, hopelessness, and depressiveness) are subject to considerable within-person variability over short time periods $[10,11]$. It is noteworthy that these fluctuations appeared in very short time frames (i.e., intervals of 30 minutes up to few hours) in our study. This finding clearly supports the necessity of assessing SI repeatedly and in real-time to obtain ecologically valid insights in the onset and course of SI [1,14].

\subsection{Real-time associations between SI and interpersonal variables}

As expected, according to the IPTS [16] and previous evidence from other, mostly cross-sectional, studies [17,18], PB and TB showed positive concurrent associations with passive SI beyond the effect of hopelessness and depressiveness, generally supporting the pathway to passive SI specified in the IPTS. Yet in the prospective analyses, we found an association between $\mathrm{PB}$ and passive SI only. For active SI, a different picture emerged: PB, $\mathrm{TB}$, depressiveness, and hopelessness co-occurred with active SI, while the interaction term of PB and TB was not significant in the cross-sectional model. Interestingly, hopelessness and PB as well as the interaction term significantly predicted active SI prospectively (models $4 \mathrm{a}$ and $4 \mathrm{~b}$ ). The effect of the interaction appeared to be small, which is in line with meta-analytic evidence from cross-sectional studies showing that the effect of the two-way interaction between PB and TB is relatively weak in comparison to the mostly moderately sized main effects of $\mathrm{PB}$ and TB [18]. Additional support for the concurrent and prospective value of the interaction between $\mathrm{PB}$ and $\mathrm{TB}$ was provided by a recent daily diary study [23]. Hence, the divergence between cross-sectional and prospective analysis in our study might be a result of the limited power to detect small effects and the lower base rate of active SI (compared to passive SI) in the investigated sample.

The finding that PB seems to be a more valid predictor for SI than TB is well-known from a number of previous studies with cross-sectional designs [48-52] and is also in line with metaanalytic evidence showing that $\mathrm{PB}$ is a more robust prospective predictor of suicidal thoughts [18]. Using an EMA approach, Kleiman et al. [10] have found concurrent associations between the interpersonal variables, hopelessness, and SI, but could not demonstrate any prospective associations when accounting for the autocorrelation of SI., Our study further supports initial evidence for the prospective value of the interpersonal variables [23] and provides partial evidence for the assumptions of the IPTS employing prospective analysis (especially regarding the link between PB and SI). The rather small effects found in our study, however, cast doubt on the clinical utility of the results as has been 
Table 2

Parameter estimates for multilevel models with passive suicidal ideation as outcome variable (models 1 and 2 ).

\begin{tabular}{|c|c|c|c|c|c|c|}
\hline \multirow[b]{2}{*}{$\begin{array}{l}\text { Model } \\
\quad \text { Predictors }\end{array}$} & \multicolumn{5}{|c|}{ Fixed effects } & \multirow{2}{*}{$\begin{array}{l}\text { Random effects } \\
\text { Slopes }>0^{1}\end{array}$} \\
\hline & Est. & 95\% CI (Est.) & SE & $\mathrm{t}(\mathrm{df})$ & $\mathrm{p}$ & \\
\hline \multicolumn{7}{|l|}{ Baseline model } \\
\hline Intercept & 2.52 & $2.01-3.03$ & 0.26 & $9.72(73)$ & $<.001$ & \\
\hline Passive suicidal ideation (t-1) & 0.40 & $.34-.46$ & 0.03 & $13.54(73)$ & $<.001$ & $98 \%$ \\
\hline \multicolumn{7}{|l|}{ Model 1} \\
\hline Intercept & 2.52 & $2.01-3.03$ & 0.26 & $9.72(73)$ & $<.001$ & \\
\hline Depressiveness & 0.07 & $.03-.11$ & 0.02 & $3.68(73)$ & $<.001$ & $73 \%$ \\
\hline Hopelessness & 0.41 & $.35-.47$ & 0.03 & $13.49(73)$ & $<.001$ & $97 \%$ \\
\hline $\mathrm{PB}$ & 0.09 & $.05-.13$ & 0.02 & $3.68(73)$ & $<.001$ & $72 \%$ \\
\hline TB & 0.04 & $.00-.08$ & 0.02 & $2.51(73)$ & .014 & $71 \%$ \\
\hline Passive suicidal ideation ( $\mathrm{t}-1)$ & 0.15 & $.11-.19$ & 0.02 & $7.04(73)$ & $<.001$ & $88 \%$ \\
\hline \multicolumn{7}{|c|}{ Quasi $\mathrm{R}^{2}$ : Predictors of model 1 account for $9.8 \%$ of residual variance in passive suicidal ideation at level $1^{2}$} \\
\hline \multicolumn{7}{|l|}{ Model 2} \\
\hline Intercept & 2.52 & $2.07-2.97$ & 0.23 & $9.72(73)$ & $<.001$ & \\
\hline Depressiveness (t-1) & 0.03 & $-.01-.07$ & 0.02 & $1.31(73)$ & .195 & $60 \%$ \\
\hline Hopelessness (t-1) & 0.08 & $.02-.14$ & 0.03 & $2.79(73)$ & .007 & $73 \%$ \\
\hline $\mathrm{PB}(\mathrm{t}-1)$ & 0.09 & $.03-.15$ & 0.03 & $3.41(73)$ & .001 & $73 \%$ \\
\hline TB $(t-1)$ & 0.00 & $-.03-.04$ & 0.02 & $-0.01(73)$ & .990 & $50 \%$ \\
\hline Passive suicidal ideation(t-1) & 0.26 & $.20-.32$ & 0.03 & $7.88(73)$ & $<.001$ & $92 \%$ \\
\hline
\end{tabular}

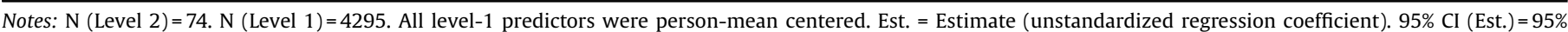

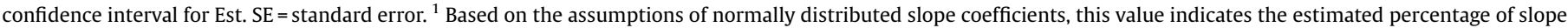
coefficients that are positive ${ }^{36}$.

${ }^{2}$ Quasi $\mathrm{R}^{2}$ indicates the change of the residual variance in passive suicidal ideation when adding the models' level 1 predictors compared to the baseline models ${ }^{40}$.

previously discussed $[3,18]$ and point out that the postulates of the IPTS might not fully capture the variety of individual influences and trajectories of SI.

\subsection{Real-time associations between hopelessness, depression, and SI}

Notably, hopelessness had the most robust and largest effect on SI across all cross-sectional and prospective models. The importance of hopelessness as a risk factor for suicidality (especially for SI) has previously been demonstrated in a multitude of studies assessing hopelessness via questionnaires $[7,8,53,54]$. For state hopelessness assessed in real-time, findings are inconclusive: While Kleiman et al. [11] found hopelessness being associated with concurrent and subsequent SI (which did not hold when controlling for preceding SI, however), others [6] could not detect a relation between hopelessness and subsequent SI (when accounting for preceding SI). Despite the specific role of hopelessness about PB and TB in the IPTS [16], this aspect has been fairly neglected by the majority of studies examining the IPTS including our own [18]. In light of the relevance of general hopelessness in our results we would strongly recommend to include hopelessness regarding the changeability of PB and TB in future investigations. The effect of depressiveness on SI was less robust in our study: While depressiveness was associated with SI in all our cross-sectional analyses, it had no predictive effect in the prospective analyses contradicting previous studies [6,55]. However, these studies slightly differed from ours in terms of methodology (items, EMA assessment).

\subsection{Strengths and limitations}

To the best of our knowledge, this is the first EMA-study that distinguishes between passive and active SI, allowing for empirically testing specific IPTS assumptions $[10,16,18]$. Besides other notable strengths (excellent compliance, assessing all variables with two reliable and valid EMA items [25]), our findings should be considered in the context of several limitations. We examined a rather homogeneous sample of depressed inpatients, and active SI was reported by 61 of 74 participants (82\%). Moreover, only $46.7 \%$ of eligible inpatients consented to participate in the study further limiting the generalizability of our findings. While our findings can be integrated in the available empirical evidence on short-term variability of SI and its risk factors $[19,20,23]$ and the IPTS $[10,18,23]$, further research in other clinical and non-clinical populations is needed to underpin the generaliziability of the findings. Although suicide research needs new and objective ways of measuring suicide risk (e.g., indirect measures of suiciderelated variables as well as behavioral proxies $[1,18]$ ), we only used self-reports. Because data on the temporal course of SI and its risk factors is still scarce [19,20], it is also unclear if our sampling strategy fits the dynamics of its natural course [12,56]. Moreover, it remains unclear whether a satisfactory operationalization of the IPTS constructs has already been attained by the available instruments and items such as the INQ [31]. While, overall, our EMA items showed good reliability and convergent validity with the commonly used INQ [25], psychometric limitations of this operationalization apply to our study as well potentially limiting the ability to draw conclusions on the validity of the IPTS [18].

\subsection{Conclusion}

One of the strongest clinical implications of this study is the need to assess SI and its risk factors repeatedly in short time frames of hours and days (as has been recommended before) $[1,14]$ ). Future studies might extend observations to longer periods of several weeks to gain more insight in the individual occurrence, course, and decline of SI $[25,56]$. Although we could identify variables that predicted changes in SI prospectively, the effects generally appear to be small and only partially in line with 
Table 3

Parameter estimates for multilevel models with active suicidal ideation as outcome variable (models 3 and 4 ).

\begin{tabular}{|c|c|c|c|c|c|c|}
\hline \multirow[b]{2}{*}{$\begin{array}{l}\text { Model } \\
\quad \text { Predictors }\end{array}$} & \multicolumn{5}{|c|}{ Fixed effects } & \multirow{2}{*}{$\begin{array}{l}\text { Random effects } \\
\text { Slopes }>0^{1}\end{array}$} \\
\hline & Est. & 95\% CI (Est.) & SE & $t(d f)$ & $\mathrm{p}$ & \\
\hline \multicolumn{7}{|l|}{ Baseline model } \\
\hline Intercept & 1.16 & $.83-1.49$ & 0.17 & $6.76(73)$ & $<.001$ & \\
\hline Active suicidal ideation ( $t-1$ ) & 0.39 & $.31-.47$ & 0.04 & $10.19(73)$ & $<.001$ & $95 \%$ \\
\hline \multicolumn{7}{|l|}{ Model 3a } \\
\hline Intercept & 1.16 & $.83-1.49$ & 0.17 & $6.76(73)$ & $<.001$ & \\
\hline Depressiveness & 0.09 & $.05-.13$ & 0.02 & $5.19(73)$ & $<.001$ & $79 \%$ \\
\hline Hopelessness & 0.14 & $.10-.18$ & 0.02 & $5.77(73)$ & $<.001$ & $81 \%$ \\
\hline $\mathrm{PB}$ & 0.05 & $.01-.09$ & 0.02 & $2.76(73)$ & .007 & $70 \%$ \\
\hline TB & 0.03 & $-.01-.07$ & 0.02 & $2.02(73)$ & .047 & $64 \%$ \\
\hline Active suicidal ideation (t-1) & 0.24 & $.18-.30$ & 0.03 & $7.18(73)$ & $<.001$ & $88 \%$ \\
\hline \multicolumn{7}{|c|}{ Quasi $\mathrm{R}^{2}$ : Predictors of model 3 account for $8.9 \%$ of residual variance in active suicidal ideation at level $1^{2}$} \\
\hline \multicolumn{7}{|l|}{ Model $3 b$} \\
\hline Intercept & 1.16 & $.83-1.49$ & 0.17 & $6.75(73)$ & $<.001$ & \\
\hline Depressiveness & 0.09 & $.05-.13$ & 0.02 & $5.42(73)$ & $<.001$ & $79 \%$ \\
\hline Hopelessness & 0.14 & $.10-.18$ & 0.02 & $5.70(73)$ & $<.001$ & $80 \%$ \\
\hline PB & 0.03 & $-.03-.09$ & 0.03 & $1.01(73)$ & .283 & $57 \%$ \\
\hline TB & 0.02 & $-.02-.06$ & 0.02 & $0.80(73)$ & .428 & $56 \%$ \\
\hline PBxTB & 0.01 & $-.01-.03$ & 0.01 & $1.42(73)$ & .159 & $59 \%$ \\
\hline Active suicidal ideation ( $\mathrm{t}-1)$ & 0.23 & $.15-.31$ & 0.04 & $6.70(73)$ & $<.001$ & $86 \%$ \\
\hline \multicolumn{7}{|c|}{ Quasi $\mathrm{R}^{2}$ : Predictors of model 4 account for $9.2 \%$ of residual variance in active suicidal ideation at level $1^{2}$} \\
\hline \multicolumn{7}{|l|}{ Model $4 a$} \\
\hline Intercept & 1.16 & $.83-1.49$ & 0.17 & $6.76(73)$ & $<.001$ & \\
\hline Depressiveness $(t-1)$ & 0.01 & $-.01-.03$ & 0.01 & $1.00(73)$ & .321 & $62 \%$ \\
\hline Hopelessness (t-1) & 0.05 & $.01-.09$ & 0.02 & $2.28(73)$ & .025 & $67 \%$ \\
\hline $\mathrm{PB}(\mathrm{t}-1)$ & 0.04 & $.00-.08$ & 0.02 & $2.11(73)$ & .038 & $65 \%$ \\
\hline $\mathrm{TB}(\mathrm{t}-1)$ & -0.01 & $-.03-.01$ & 0.01 & $-0.77(73)$ & .444 & $41 \%$ \\
\hline Active suicidal ideation ( $\mathrm{t}-1)$ & 0.32 & $.24-.40$ & 0.04 & $8.84(73)$ & $<.001$ & $93 \%$ \\
\hline \multicolumn{7}{|c|}{ Quasi $\mathrm{R}^{2}$ : Predictors of model 5 account for $1.2 \%$ of residual variance in active suicidal ideation at level $1^{2}$} \\
\hline \multicolumn{7}{|l|}{ Model $4 b$} \\
\hline Intercept & 1.16 & $.83-1.49$ & 0.17 & $6.76(71)$ & $<.001$ & \\
\hline Depressiveness $(\mathrm{t}-1)$ & 0.01 & $-.01-.03$ & 0.01 & $1.18(73)$ & .242 & $62 \%$ \\
\hline Hopelessness (t-1) & 0.05 & $.01-.09$ & 0.02 & $2.38(73)$ & .020 & $68 \%$ \\
\hline $\mathrm{PB}(\mathrm{t}-1)$ & -0.01 & $-.05-.03$ & 0.02 & $-0.28(73)$ & .781 & $48 \%$ \\
\hline $\mathrm{TB}(\mathrm{t}-1)$ & -0.06 & $-.10-(-.02)$ & 0.02 & $-2.78(73)$ & .007 & $28 \%$ \\
\hline $\operatorname{PBxTB}(\mathrm{t}-1)$ & 0.01 & $.01-.01$ & 0.00 & $2.61(73)$ & .011 & $70 \%$ \\
\hline Active suicidal ideation $(\mathrm{t}-1)$ & 0.32 & $.24-.40$ & 0.04 & $8.50(73)$ & $<.001$ & $92 \%$ \\
\hline
\end{tabular}

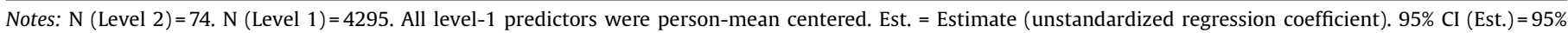
confidence interval for Est. $\mathrm{SE}=$ standard error.

${ }^{1}$ Based on the assumptions of normally distributed slope coefficients, this value indicates the estimated percentage of slope coefficients that are positive. ${ }^{36}$

${ }^{2}$ Quasi $\mathrm{R}^{2}$ indicates the change of the residual variance in active suicidal ideation when adding the models' level 1 predictors compared to the baseline models. ${ }^{40}$

theoretical assumptions warranting further investigation. It might be useful to focus specifically on person-level or cross-level effects or to conduct subgroup analyses (i.e., differentiate between persons experiencing passive and active SI or persons with and without suicide attempt history). Because of the low base rate of persons experiencing active SI and with a history of suicide attempt(s), such analyses were not possible in our study for reasons of power. More complex models such as the Integrated Motivational-Volitional model of suicidal behavior [57] that include more variables that serve as moderator or mediator in the development of SB might also lead to larger effects because of the combination of several predictors.

\section{Potential conflicts of interest}

None.

\section{Funding}

This research was supported by research grants no. SP 1556/1-1, GL 818/1-1 and FO 784/1-1 from the German Research Foundation.

\section{Role of the sponsor}

The supporters had no role in the design, analysis, interpretation, or publication of this study.

\section{Previous presentation}

Poster presented at the IASR/AFSP International Summit on Suicide Research, Henderson, Nevada, November 5-8, 2017. Poster presented at the 5th Biennial Conference of the Society for Ambulatory Assessment, Luxembourg, June 15-17, 2017. Presentation at the IASR/AFSP International Summit on Suicide Research, Henderson, Nevada, November 7th, 2017. Presentation at the 16th European Symposium for Suicide and Suicidal Behavior, Oviedo, Spain, September, 9th, 2016, Presentation at the German Congress for Psychosomatic Medicine and Psychotherapy (DKPM), Berlin, Germany, March, 8th, 2018.

\section{References}

[1] Glenn CR, Nock MK. Improving the short-term prediction of suicidal behavior Am J Prev Med 2014;47(3 Suppl 2)S176-80, doi:http://dx.doi.org/10.1016/j. amepre.2014.06.004 PubMed PMID: 25145736. 
[2] O'Connor RC, Nock MK. The psychology of suicidal behaviour. Lancet Psychiatry 2014;1(1):73-85, doi:http://dx.doi.org/10.1016/S2215-0366(14) 70222-6.

[3] Franklin JC, Ribeiro JD, Fox KR, Bentley KH, Kleiman EM, Huang X, et al. Risk factors for suicidal thoughts and behaviors: a meta-analysis of 50 years of research. Psychol Bull 2017;143(2)187-232, doi:http://dx.doi.org/10.1037/ bul0000084 PubMed PMID: 27841450.

[4] Hawton K, Casañas I, Comabella C, Haw C, Saunders K. Risk factors for suicide in individuals with depression: a systematic review. J Affect Disord 2013;147 (1-3)17-28, doi:http://dx.doi.org/10.1016/j.jad.2013.01.004 PubMed PMID: 23411024.

[5] Brown GK, Beck AT, Steer RA, Grisham JR. Risk factors for suicide in psychiatric outpatients: a 20-year prospective study. J Consult Clin Psychol 2000;68 (3):371-7.

[6] Ben-Zeev D, Young MA, Depp CA. Real-time predictors of suicidal ideation: mobile assessment of hospitalized depressed patients. Psychiatry Res 2012;197(1-2)55-9, doi:http://dx.doi.org/10.1016/j.psychres.2011.11.025 PubMed PMID: 22397912.

[7] Nock MK, Kazdin AE. Examination of affective, cognitive, and behavioral factors and suicide-related outcomes in children and young adolescents. J Clin Child Adolesc Psychol 2002;31(1):48-58, doi:http://dx.doi.org/10.1207/ 153744202753441666.

[8] Wang Y, Jiang N, Cheung EFC, Sun H, Chan RCK. Role of depression severity and impulsivity in the relationship between hopelessness and suicidal ideation in patients with major depressive disorder. I Affect Disord 2015;183:83-9, doi:http://dx.doi.org/10.1016/j.jad.2015.05.001 PubMed PMID: 26001667.

[9] Rudd MD, Berman AL, Joiner TE, Nock MK, Silverman MM, Mandrusiak M, et al. Warning signs for suicide: theory, research, and clinical applications. Suicide Life Threat Behav 2006;36(3):255-62.

[10] Kleiman EM, Turner BJ, Fedor S, Beale EE, Huffman JC, Nock MK. Examination of real-time fluctuations in suicidal ideation and its risk factors: results from two ecological momentary assessment studies. J Abnorm Psychol 2017, doi:http:// dx.doi.org/10.1037/abn0000273 PubMed PMID: 28481571.

[11] Hallensleben N, Spangenberg L, Forkmann T, Rath D, Hegerl U, Kersting A, et al. Investigating the dynamics of suicidal ideation. Crisis 2018;39:65-9, doi: http://dx.doi.org/10.1027/0227-5910/a000464.

[12] Verhagen SJW, Hasmi L, Drukker M, van Os J, Delespaul PAEG. Use of the experience sampling method in the context of clinical trials. Evid Based Men Health 2016;19(3)86-9, doi:http://dx.doi.org/10.1136/ebmental-2016-102418 PubMed PMID: 27443678.

[13] Santangelo P, Ebner-Priemer U, Trull TJ. Experience sampling methods in clinical psychology. In: Comer J, Kendall P, editors. The Oxford handbook of research strategies for clinical psychology. Oxford University Press; 2013. p. 188-210 eng.

[14] de Beurs D, Kirtley O, Kerkhof A, Portzky G, O'Connor RC. The role of mobile phone technology in understanding and preventing suicidal behavior. Crisis 2015;36(2):79-82, doi:http://dx.doi.org/10.1027/0227-5910/ a000316.

[15] Joiner TE. Why people die by suicide. Cambridge, MA: Harvard University Press; 2005.

[16] Van Orden KA, Witte TK, Cukrowicz KC, Braithwaite SR, Selby EA, Joiner TE. The interpersonal theory of suicide. Psychol Rev 2010;117(2):575-600.

[17] Ma J, Batterham PJ, Calear AL, Han J. A systematic review of the predictions of the interpersonal-psychological theory of suicidal behavior. Clin Psychol Rev 2016;46:34-45, doi:http://dx.doi.org/10.1016/j.cpr.2016.04.008 PubMed PMID: 27155061.

[18] Chu C, Buchman-Schmitt JM, Stanley IH, Hom MA, Tucker RP, Hagan CR, et al. The interpersonal theory of suicide: a systematic review and meta-analysis of a decade of cross-national research. Psychol Bull 2017, doi:http://dx.doi.org/ 10.1037/bul0000123 PubMed PMID: 29072480.

[19] Spangenberg L, Forkmann T, Glaesmer H. Investigating dynamics and predictors of suicidal behaviors using ambulatory assessment. Neuropsychiatr 2015;29(3)139-43, doi:http://dx.doi.org/10.1007/s40211-0150142-1 PubMed PMID: 25868681.

[20] Kleiman EM, Nock MK. Real-time assessment of suicidal thoughts and behaviors. Curr Opin Psychol [Internet] 2018;22:33-7. . Available from: http:// www.sciencedirect.com/science/article/pii/S2352250X1730163X.

[21] Palmier-Claus JE, Taylor PJ, Gooding P, Dunn G, Lewis SW. Affective variability predicts suicidal ideation in individuals at ultra-high risk of developing psychosis: an experience sampling study. Br J Clin Psychol 2012;51(1)72-83, doi:http://dx.doi.org/10.1111/j.2044-8260.2011.02013.x PubMed PMID: 22268542.

[22] Links PS, Eynan R, Heisel MJ, Barr A, Korzekwa M, McMain S, et al. Affective instability and suicidal ideation and behavior in patients with borderline personality disorder. J Pers Disord 2007;21(1):72-86.

[23] Czyz EK, Horwitz AG, Arango A, King CA. Short-term change and prediction of suicidal ideation among adolescents: a daily diary study following psychiatric hospitalization. J Child Psychol Psychiatry 2018, doi:http://dx.doi.org/10.1111/ jcpp.12974.

[24] Sokero TP, Melartin TK, Rytsala HJ, Leskela US, Lestela-Mielonen PS, Isomets ET. Suicidal ideation and attempts among psychiatric patients with major depressive disorder. J Clin Psychiatry 2003;64(9):1094-100.

[25] Forkmann T, Spangenberg L, Rath D, Hallensleben N, Hegerl U, Kersting A, et al. Assessing suicidality in real time: a psychometric evaluation of self-report items for the assessment of suicidal ideation and its proximal risk factors using ecological momentary assessments. J Abnorm Psychol 2018, doi:http://dx.doi. org/10.1037/abn0000381.

[26] Lehrl S. Mehrfachwahl-Wortschatz-Intelligenztest (MWT-B). 5th ed. Balingen: Spitta; 2005.

[27] Wittchen H, Zaudig M, Fydrich T. Strukturiertes klinisches interview für DSMIV. Göttingen: Hogrefe; 1997 de.

[28] movisens GmbH. movisensXS, Version 0.7.4162. Karlsruhe, Germany.

[29] Gruehn D, Kotter-Gruehn D, Roecke C. Discrete affects across the adult lifespan: evidence for multidimensionality and multidirectionality of affective experiences in young, middle-aged and older adults. J Res Pers 2010;44 (4):492-500, doi:http://dx.doi.org/10.1016/j.jrp.2010.06.003.

[30] Glaesmer H, Spangenberg L, Scherer A, Forkmann T. Assessing desire for suicide: first results on psychometric properties of the German version of the Interpersonal Needs Questionnaire (INQ). Psychiatr Prax 2014;41(5):250-6.

[31] Hallensleben N, Spangenberg L, Kapusta ND, Forkmann T, Glaesmer H. The German version of the Interpersonal Needs Questionnaire (INQ) Dimensionality, psychometric properties and population-based norms. J Affect Disord 2016;195:191-8, doi:http://dx.doi.org/10.1016/j.jad.2016.01.045.

[32] Kliem S, Brähler E. Beck hopelessness scale (Beck Hoffnungslosigkeitsskala) (BHS) Halbergmoos: Pearson. 2015.

[33] Paykel ES, Myers JK, Lindenthal JJ, Tanner J. Suicidal feelings in general population - prevalence study. Br J Psychiatry 1974;124(MAY):460-9, doi: http://dx.doi.org/10.1192/bjp.124.5.460.

[34] Miller IW, Norman WH, Bishop SB, Dow MG. The modified scale for suicidal ideation - reliability and validity. J Consult Clin Psychol 1986;54(5):724-5.

[35] Kliem S, Brähler E. Beck-suizidgedanken-Skala (BSS): deutsche fassung. $1^{\text {st }}$ ed. Frankfurt am Main: Pearson Assessment \& Information GmbH; 2015. p. 76.

[36] Forkmann T, Boecker M, Wirtz M, Eberle N, Westhofen M, Schauerte P, et al. Development and validation of the Rasch-based depression screening (DESC) using Rasch analysis and structural equation modelling. J Behav Ther Exp Psychiatry 2009;40(3):468-78.

[37] Raudenbusch SW, Bryk AS, Congdon RT. HLM: hierarchical linear and nonlinear modeling. Scientific Software International; 2010. p. en.

[38] Wickham H. ggplot2: elegant graphics for data analysis. New York: Springer; 2009.

[39] R Core Team. R: a language and environment for statistical computing. Vienna, Austria: R Foundation of Statistical Computing; 2015 en.

[40] Hox JH. Multilevel analysis: techniques and application. $2^{\text {nd }}$ ed. New York: Routledge; 2010 en.

[41] Woyshville MJ, Lackamp JM, Eisengart JA, Gilliland JA. On the meaning and measurement of affective instability: clues from chaos theory. Biol Psychiatry 1999;45(3)261-9 PubMed PMID: 10023499.

[42] Hayes AF. A primer on multilevel modeling. Human Comm Res. 2006;32 (4):385-410, doi:http://dx.doi.org/10.1111/j.1468-2958.2006.00281.x.

[43] Snijders TA, Bosker RJ. Modeled variance in two-level models. Sociol Methods Res 2016;22(3):342-63, doi:http://dx.doi.org/10.1177/ 0049124194022003004

[44] LaHuis DM, Hartman MJ, Hakoyama S, Clark PC. Explained variance measures for multilevel models. Organ Res Methods 2014;17(4):433-51, doi:http://dx. doi.org/10.1177/1094428114541701.

[45] Snijders. Multilevel analysis. [Place of publication not identified]. Sage Publications; 2011 pages.

[46] Enders CK, Tofighi D. Centering predictor variables in cross-sectional multilevel models: a new look at an old issue. Psychol Methods 2007;12(2) 121-38, doi:http://dx.doi.org/10.1037/1082-989X.12.2.121 PubMed PMID: 17563168.

[47] Kleiman EM. Power curves for multi-level studies [cited March $1^{\text {st }} 2018$ ]. Available from:. https://ekleiman.shinyapps.io/powercurves/.

[48] Hill RM, Pettit JW. Suicidal ideation and sexual orientation in college students: the roles of perceived burdensomeness, thwarted belongingness, and perceived rejection due to sexual orientation. Suicide Life Threat Behav 2012;42(5)567-79, doi:http://dx.doi.org/10.1111/j.1943-278X.2012.00113.x PubMed PMID: 22882479.

[49] Lamis DA, Lester D. Risk factors for suicidal ideation among african american and european american college women. Psychol Women Q 2012;36(3):33749, doi:http://dx.doi.org/10.1177/0361684312439186.

[50] Cole AB, Wingate LR, Slish ML, Tucker RP, Hollingsworth DW, O'Keefe VM. Burdensomeness, depression, and suicide in a sample of American-Indian college students. Ethnicity Inequalities HSC 2013;6(2/3):77-86, doi:http://dx. doi.org/10.1108/EIHSC-10-2013-0026

[51] Bryan CJ, Clemans TA, Hernandez AM. Perceived burdensomeness, fearlessness of death, and suicidality among deployed military personnel. Pers Individ Dif 2012;52(3):374-9.

[52] Bryan CJ, Morrow CE, Anestis MD, Joiner TE. A preliminary test of the interpersonal-psychological theory of suicidal behavior in a military sample. Pers Individ Dif 2010;48(3):347-50.

[53] Beevers CG, Miller IW. Perfectionism, cognitive bias, and hopelessness as prospective predictors of suicidal ideation. Suicide Life Threat Behav 2004;34 (2)126-37, doi:http://dx.doi.org/10.1521/suli.34.2.126.32791 PubMed PMID: 15191269.

[54] Brezo J, Paris J, Turecki G. Personality traits as correlates of suicidal ideation, suicide attempts, and suicide completions: a systematic review. Acta Psychiatr Scand 2006;113(3)180-206, doi:http://dx.doi.org/10.1111/j.16000447.2005.00702.x PubMed PMID: 16466403.

[55] Husky M, Swendsen J, Ionita A, Jaussent I, Genty C, Courtet P. Predictors of daily life suicidal ideation in adults recently discharged after a serious suicide 
attempt: a pilot study. Psychiatry Res 2017;256:79-84, doi:http://dx.doi.org/ 10.1016/j.psychres.2017.06.035 PubMed PMID: 28624676.

[56] Ebner-Priemer U, Trull TJ. Investigating the temporal instability in psychological variables: understanding the real world as time dependent. In: Mehl MR, Conner TS, editors. Handbook of research methods for studying daily life. New York: Guilford Press; 2012. p. en.

[57] O'Connor RC. The integrated motivational-volitional model of suicidal behavior. Crisis J Crisis Interv. Suicide Prev. 2011;32(6):295-8, doi:http://dx. doi.org/10.1027/0227-5910/a000120.

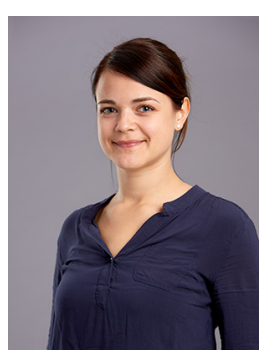

Nina Hallensleben is a psychologist by training and is currently PhD Student at the Department of Medical Psychology and Medical Sociology, University of Leipzig University, Germany.

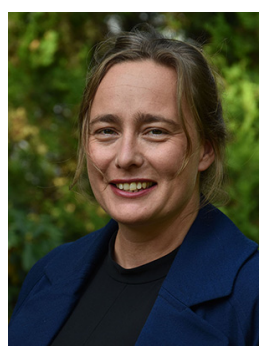

Heide Glaesmer is a psychologist and CBT therapist by training. She is the deputy head of the Department of Medical Psychology and Medical Sociology, University of Leipzig, Germany.

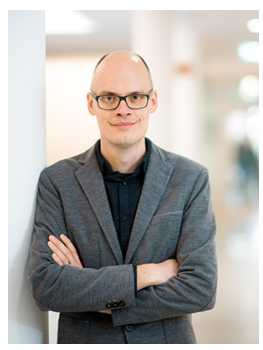

Thomas Forkmann is psychologist and CBT therapist by training. He is the head of Department of Clinical Psychology at the University of Duisburg-Essen, Germany.

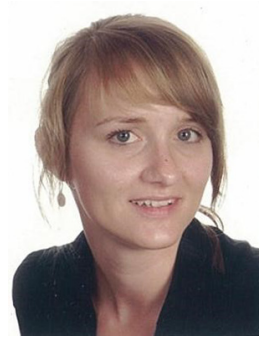

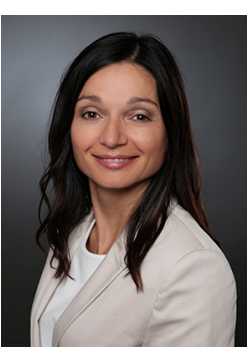

Maria Strauss is a senior physician in psychiatry and psychotherapy at the Department of Psychiatry and Psychotherapy at the University hospital Leipzig, Germany.

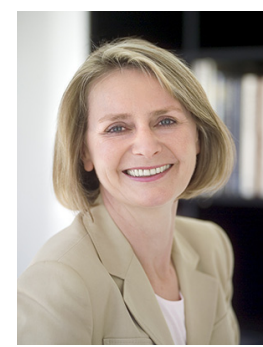

Annette Kersting is Professor of Psychosomatic Medicine and Psychotherapy and the Director of the Clinic and Policlinic of Psychosomatic Medicine and Psychotherapy at the University hospital Leipzig, Germany

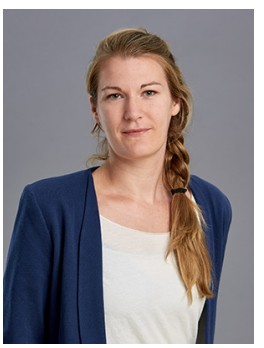

Lena Spangenberg is a psychologist by training and postdoc researcher. Together with Heide Glaesmer she is the head of the working group "Suicidality research" at the Department of Medical Psychology and Medical Sociology, University of Leipzig, Germany. 